\title{
Pt-Ni Aerogels as Unsupported Electrocatalysts for the Oxygen Reduction Reaction
}

\author{
Sebastian Henning, a, = Laura Kühn,, , = Juan Herranz, ${ }^{\text {a, }, \text { z }}$ Julien Durst, ${ }^{\text {a }}$ Tobias Binninger, ${ }^{\text {a }}$ \\ Maarten Nachtegaal, ${ }^{\mathrm{c}}$ Matthias Werheid, ${ }^{\mathrm{b}}$ Wei Liu, ${ }^{\mathrm{b}}$ Marion Adam, ${ }^{\mathrm{d}}$ Stefan Kaskel, ${ }^{\mathrm{d}}$ \\ Alexander Eychmüller, ${ }^{\text {b }}$ and Thomas J. Schmidt ${ }^{\text {a,e,* }}$
}

${ }^{a}$ Electrochemistry Laboratory, Paul Scherrer Institut, 5232 Villigen, Switzerland

${ }^{b}$ Physical Chemistry, Technische Universität Dresden, 01062 Dresden, Germany

${ }^{c}$ Paul Scherrer Institut, 5232 Villigen, Switzerland

${ }^{d}$ Chair of Inorganic Chemistry I, Technische Universität Dresden, 01062 Dresden, Germany

${ }^{e}$ Laboratory of Physical Chemistry, ETH Zurich, 8093 Zurich, Switzerland

\begin{abstract}
The commercial feasibility of polymer electrolyte fuel cells (PEFCs) passes by the development of Pt-based, $\mathrm{O}_{2}$-reduction catalysts with greater activities and/or lower Pt-contents, as well as an improved stability. In an effort to tackle these requirements, unsupported bimetallic Pt-Ni nanoparticles (NPs) interconnected in the shape of nanochain networks (aerogels) were synthesized using a simple one-step reduction and gel formation process in aqueous solution. The products of this novel synthetic route were characterized by X-ray absorption spectroscopy to elucidate the materials' structure. Using electrochemical experiments, we probed the surface composition of the as-synthesized aerogels and of equivalent materials exposed to acid, and concluded that a Ni-(hydr)oxide side phase is present in the aerogel with a larger Ni-concentration. Regardless of this initial surface composition, the Pt-Ni aerogels feature $\mathrm{a} \approx 3$-fold increase of surface-specific ORR activity when compared to a commercial platinum-on-carbon catalyst, reaching the mass-specific requirement for application in automotive PEFCs.

(C) The Author(s) 2016. Published by ECS. This is an open access article distributed under the terms of the Creative Commons Attribution 4.0 License (CC BY, http://creativecommons.org/licenses/by/4.0/), which permits unrestricted reuse of the work in any medium, provided the original work is properly cited. [DOI: 10.1149/2.0251609jes] All rights reserved.
\end{abstract}

Manuscript submitted May 6, 2016; revised manuscript received June 17, 2016. Published June 29, 2016.

State-of-the-art polymer electrolyte fuel cells (PEFCs) require large amounts of carbon-supported platinum nanoparticle $(\mathrm{Pt} / \mathrm{C})$ catalysts $\left(\approx 0.4 \mathrm{mg}_{\mathrm{Pt}} / \mathrm{cm}^{2} \text { electrode }\right)^{1}$ to account for the large overpotential of the oxygen reduction reaction (ORR). Thus, Pt contributes significantly to the fuel cell system cost, and progress to reduce its loading is crucial to meet the long-term PEFC cost target of $40 \$ / \mathrm{kW}$ set by the U. S. Department of Energy (DOE). ${ }^{2}$ One approach to reduce this excessive Pt-loading relies on increasing the catalysts' ORR activity, e.g. by alloying platinum with other metals like $\mathrm{Ni}, \mathrm{Cu}$ and $\mathrm{Co}$, to form materials which show up to one order of magnitude higher mass-specific activity than commercial $\mathrm{Pt} / \mathrm{C}$ catalysts. ${ }^{3}$ On the other hand, these carbon-supported materials suffer from significant carbonand Pt-corrosion during the standard operation of PEFCs, gradually compromising their efficiency and reliability. ${ }^{4}$ To partially overcome stability issues, research focuses on unsupported materials (e.g. Ptcoated $\mathrm{Ni}, \mathrm{Co}$ or $\mathrm{Cu}$ nanowires ${ }^{5-7}$ ) besides extended metal surfaces (e.g. $3 \mathrm{M}$ nanostructured thin film catalysts ${ }^{8}$ ) or alternative supports (e.g. conductive metal oxides ${ }^{9-12}$ ). Naturally, those materials should be processable into catalytic layer architectures that provide reactant and product diffusion pathways similar to those in conventional $\mathrm{Pt} / \mathrm{C}$ electrodes to guarantee high catalyst utilization and PEFC performance. ${ }^{13}$

To meet the requirements mentioned above, un-supported bimetallic electrocatalysts with high surface area (up to $\approx 80 \mathrm{~m}^{2} / \mathrm{g}_{\text {metal }}$ ) and nanochain network structure, referred to as aerogels, have been synthesized. ${ }^{14-16}$ The synthetic routes to prepare such materials vary, but generally involve the use of stabilizing surfactants and/or organic solvents ${ }^{17-19}$ that can poison the catalyst's surface and decrease its activity. In contrast to those approaches, our groups have developed a facile one-step synthesis for mono- and bimetallic aerogels based on the reduction of metal salts by $\mathrm{NaBH}_{4}$ in aqueous solution without addition of stabilizing surfactants. ${ }^{20}$

On the basis of previous work on Pt-Pd alloy aerogels prepared with the aforementioned method, ${ }^{20}$ we have adapted our synthetic approach to the combination of a noble and a non-noble metal, targeting a reduced noble metal content while maintaining a high ORR activity. As we will demonstrate in this article, the combination of $\mathrm{Pt}$ and $\mathrm{Ni}$ yielded materials with a mass-normalized ORR activity $\approx 2$-fold

\footnotetext{
$=$ These authors contributed equally to this work

*Electrochemical Society Member.

${ }^{\mathrm{z}}$ E-mail: juan.herranz@psi.ch
}

higher than that of a commercial $\mathrm{Pt} / \mathrm{C}$ catalyst and that reaches the DOE target for automotive PEFC application. ${ }^{21}$

\section{Experimental}

Pt-Ni hydrogels were prepared by a simple co-reduction route in aqueous solution under ambient conditions (room temperature, air). Briefly, Pt and Ni precursors were dissolved in water $(18.2 \mathrm{M} \Omega \mathrm{cm}$, Millipore) in the $\mathrm{Pt}^{4+}: \mathrm{Ni}^{2+}$ molar proportions required to reach the targeted Pt:Ni ratio, and reduced by $\mathrm{NaBH}_{4}$. Selecting the synthesis of $\mathrm{Pt}_{3} \mathrm{Ni}$ hydrogel as an example, $585 \mu \mathrm{L}$ of a $0.205 \mathrm{M} \mathrm{H}_{2} \mathrm{PtCl}_{6}$ solution (8 wt $\%$ in $\mathrm{H}_{2} \mathrm{O}$, Sigma Aldrich) [final reactant concentration $0.15 \mathrm{mM}$ ] and $4 \mathrm{ml}$ of a freshly prepared $10 \mathrm{mM} \mathrm{NiCl}_{2}$ solution $\left(\mathrm{NiCl}_{2}{ }^{*} 6 \mathrm{H}_{2} \mathrm{O}\right.$ $99 \%$, Sigma Aldrich) [final reactant concentration $0.05 \mathrm{mM}$ ] were dissolved in $790 \mathrm{ml}$ water and stirred until mixing was complete. Subsequently, $7.0 \mathrm{ml}$ of a freshly prepared $0.1 \mathrm{M} \mathrm{NaBH}_{4}$ solution (granular, 99.99\%, Sigma Aldrich) $\left[\mathrm{c}\left(\mathrm{Pt}^{4+}+\mathrm{Ni}^{2+}\right): \mathrm{c}\left(\mathrm{NaBH}_{4}\right)=1: 1.25\right]$ were added under vigorous stirring. Upon addition of $\mathrm{NaBH}_{4}$, the color of the solution turned immediately from light yellow to dark brown. The solution was kept stirring for another 30 min. Afterwards, the reaction solution was divided and transferred to $100 \mathrm{ml}$ vials. After about four days, black $\mathrm{Pt}_{\mathrm{x}} \mathrm{Ni}$ hydrogel was formed at the bottom of the containers. The hydrogel parts obtained from the same synthesis were collected in a small vial and washed with water. For this, half of the supernatant was removed and replaced cautiously with fresh water. This step was repeated six times. Afterwards, the solvent was exchanged stepwise with acetone. Again, half of the supernatant was removed and replaced by acetone. This step was repeated 11 times. The resulting anhydrous gels were transferred to a critical point dryer (Critical Point Dryer 13200J-AB, SPI Supplies) operating with $\mathrm{CO}_{2}$.

XAS spectra at the $\mathrm{Pt} \mathrm{L}_{3}$ and $\mathrm{Ni} \mathrm{K}$ edges were recorded at the SuperXAS beamline of the Swiss Light Source (Paul Scherrer Institut, Villigen, Switzerland), whereby the monochromator energy was calibrated using Pt and Ni foils, respectively. Measurements were performed ex-situ in transmission mode on pouch bags made from conductive Kapton tape that were filled with aerogel powder. The quickEXAFS (QEXAFS) method was used to increase time resolution; ${ }^{22}$ 100 and 600 quick-XAS spectra were recorded at the $\mathrm{Pt} \mathrm{L}_{3}$ and Ni K edges, respectively. These XAS data were first analyzed with the JAQ analyzer software which allows averaging of individual XAS spectra into a single spectrum. Subsequently, Athena of the Demeter software 
package was used for normalization and background subtraction. ${ }^{23}$ The fit of the EXAFS oscillations was performed with Artemis ${ }^{23}$ using a face centered cubic Pt-Ni structure for the paths description. Amplitude reduction terms were calculated from EXAFS fits of $\mathrm{Pt}$ and $\mathrm{Ni}$ reference foils assuming a coordination number of 12 and amounted to $\mathrm{S}_{0, \mathrm{Ni}}{ }^{2}=0.97$ and $\mathrm{S}_{0, \mathrm{Pt}}{ }^{2}=0.85$, respectively

Electrolyte solutions were prepared from $\mathrm{NaOH} \cdot \mathrm{H}_{2} \mathrm{O}$ pellets (99.995\% purity, TraceSELECT, Sigma Aldrich) or $60 \% \mathrm{HClO}_{4}$ (Kanto Chemical Co., Inc.) diluted in ultrapure water $(18.2 \mathrm{M} \Omega \mathrm{cm}$, Elga Purelab Ultra). High purity $\mathrm{N}_{2}(5.0), \mathrm{O}_{2}(5.0)$ and $\mathrm{CO}(4.7)$ were purchased from Messer AG, Switzerland. The benchmark catalyst for this study is a Pt/Vulcan XC-72 electrocatalyst with a weight fraction of 30\% purchased from E-TEK Inc. (Lot\# C0160311). The electrochemical measurements in acid were performed in a house-made three electrode glass cell. A reversible hydrogen electrode was connected to the main cell compartment through a Luggin cappilary, and a gold mesh (99,99\% metals basis, Alfa Aesar) held in a separate tube in contact with the main cell served as counter electrode (CE). The working electrode (WE) was a PTFE-made, interchangeable rotating ring-disc electrode (RRDE, Pine Research Instrumentation) equipped with a Ptring and a mirror-polished, glassy carbon disk insert ( $5 \mathrm{~mm}$ diameter, HTW Hochtemperatur-Werkstoffe GmbH). Before the measurements, the WE was mounted to a polyetheretherketone (PEEK) shaft that was attached to a modulated speed rotator (both Pine Research Instrumentation). A Biologic VSP-300 was used as potentiostat, in combination with the EC-Lab V10.44 software package. The ohmic drop was determined by electrochemical impedance spectroscopy, applying a $5 \mathrm{mV}$ perturbation $(100 \mathrm{kHz}$ to $1 \mathrm{~Hz})$ at $0.45 \mathrm{~V}_{\mathrm{RHE}}$. The setup for measurements in alkaline electrolyte was described in detail in a previous work. ${ }^{24}$ In brief, it consisted of a house-made polytetrafluoroethylene (PTFE) cell with a four-necked glass cover. A calomel reference electrode (ALS Co., Ltd.) was kept in a separated glass holder filled with electrolyte connected to the main compartment through a Luggin capillary consisting of a FEP tube closed with a $50 \mu \mathrm{m}$ thick Nafion membrane (Ion Power, New Castle, DE). The setup was completed by a gas bubbler and a gold mesh counter electrode.

Thin-film electrodes were prepared by dispersing catalyst materials in mixtures of ultrapure water $(18.2 \mathrm{M} \Omega \mathrm{cm}$, Elga Purelab Ultra) and isopropanol (99.9\%, Chromasolv Plus for HPLC, Sigma Aldrich), followed by 10 min sonication in an ultrasonic bath (USC100T, $45 \mathrm{kHz}$, VWR). Fractions of the inks were pipetted onto the glassy carbon inset of the RRDE to obtain catalyst loadings of 30 and $15 \mu \mathrm{g}_{\mathrm{Pt}} / \mathrm{cm}^{2}$ electrode for Pt-Ni aerogels and $\mathrm{Pt} / \mathrm{C}$, respectively. Subsequently, coatings were dried under a gentle $\mathrm{N}_{2}$-flux.

\section{Results and Discussion}

Bimetallic aerogels with various $\mathrm{Pt}: \mathrm{Ni}$ atomic ratios were synthesized by the simple co-reduction process of $\mathrm{NiCl}_{2} \cdot 6 \mathrm{H}_{2} \mathrm{O}$ and $\mathrm{H}_{2} \mathrm{PtCl}_{6}$ with $\mathrm{NaBH}_{4}$ in aqueous solution described in the Experimental section.

The composition of the Pt-Ni aerogels produced in this manner was determined by inductively coupled plasma-optical emission spectrometry (ICP-OES) and compared to the values expected on the basis of the initial precursor ratios. As Figure SI-1 shows, a decrease in the extent of reduction of the Ni-precursor is observed upon preparation

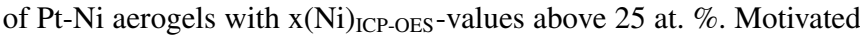
by this result, two samples were selected for further characterization and analysis: one with a final $\mathrm{Ni}$ content $\leq 25$ at. $\%\left(\mathrm{Pt}_{3} \mathrm{Ni}\right.$, $\mathrm{x}(\mathrm{Ni})_{\text {expected }} \approx \mathrm{x}(\mathrm{Ni})_{\text {ICP-OES }} \approx 25$ at. $\left.\%\right)$ and one with $>25$ at. $\% \mathrm{Ni}$ $\left(\mathrm{Pt}_{1.5} \mathrm{Ni}, \mathrm{x}(\mathrm{Ni})_{\text {expected }} \approx 50\right.$ at. $\%$ vs. $\mathrm{x}(\mathrm{Ni})_{\text {ICP-OES }} \approx 40$ at. $\left.\%\right)$.

Fig. 1 shows representative transmission electron microscopy (TEM) images of the $\mathrm{Pt}_{3} \mathrm{Ni}$ and $\mathrm{Pt}_{1.5} \mathrm{Ni}$ aerogels that look similar to those obtained for aerogels with other Pt-Ni compositions (not shown here). In agreement with previous work,$^{20}$ the materials consist of a 3D structure of nanochains that are composed of interconnected/fused nanoparticles. The quality of the nanochain network is supported by the fact that no isolated nanoparticles can be observed. Additionally, nanochain diameters from TEM images based on measurement of the

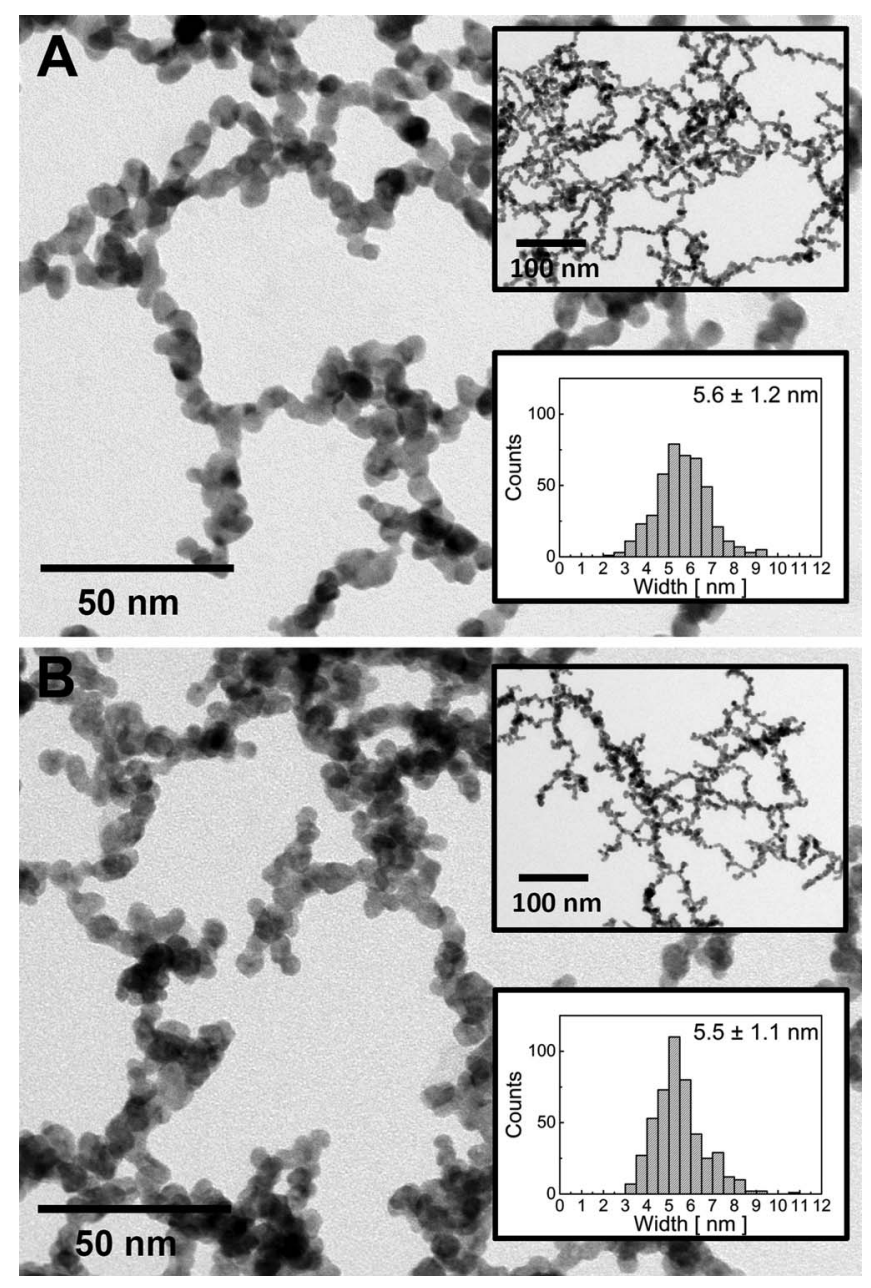

Figure 1. TEM images of $\mathrm{Pt}_{3} \mathrm{Ni}(\mathrm{A})$ and $\mathrm{Pt}_{1.5} \mathrm{Ni}(\mathrm{B})$ aerogel; the insets show the corresponding distributions of nanochain diameters and TEM images with lower magnification.

chain's width at different spots are on average $\approx 5 \mathrm{~nm}$ for both samples (cf. Table I).

To highlight the reproducibility of our synthesis, the good agreement between nanochain diameter distributions of different batches is illustrated in Fig. SI-2. Moreover, the surface areas of the aerogels were analyzed by $\mathrm{N}_{2}$-physisorption measurements (cf. Figure SI-3). Both materials exhibited a type II isotherm and a slight hysteresis indicating the presence of macropores and some mesopores. ${ }^{25}$ Surface areas were estimated from Brunauer-Emmett-Teller (BET) plots to $55 \mathrm{~m}^{2} / \mathrm{g}_{\mathrm{Pt}}$ and $58 \mathrm{~m}^{2} / \mathrm{g}_{\mathrm{Pt}}$ for $\mathrm{Pt}_{3} \mathrm{Ni}$ and $\mathrm{Pt}_{1.5} \mathrm{Ni}$, respectively (cf. Table I).

The samples were further characterized by X-ray diffraction (XRD) (see Fig. SI-4) in order to investigate alloy formation between $\mathrm{Pt}$ and $\mathrm{Ni}$. The (111) reflections at $2 \theta$-values of $40.73^{\circ}\left(\mathrm{Pt}_{3} \mathrm{Ni}\right)$ and $41.04^{\circ}\left(\mathrm{Pt}_{1.5} \mathrm{Ni}\right)$ present a shift with respect to pure $\mathrm{Pt}\left(39.83^{\circ}\right) .^{26}$ These shifts to larger angles, also observed for the (220) reflections at $\approx 67.71^{\circ}$ (pure $\mathrm{Pt}$ ), confirm alloy formation between $\mathrm{Pt}$ and $\mathrm{Ni}$. The greater $2 \theta$ shift for $\mathrm{Pt}_{1.5} \mathrm{Ni}$ compared to $\mathrm{Pt}_{3} \mathrm{Ni}$ indicates a larger $\mathrm{Ni}$-concentration in the alloy phase of this aerogel. Analysis of the XRD spectra was concluded by calculating crystallite sizes on basis of the full width at half maximum of the (111) reflections (Scherrer equation); the resulting values tabulated in Table I coincide well with the average nanochain diameters derived from TEM images.

The crystallite sizes and nanochain diameters from XRD and TEM analyses were used to calculate surface areas assuming cylindrical nanowires and compared to the respective values derived from $\mathrm{N}_{2}$ physisorption and electrochemical measurements. The latter electrochemical surface areas (ECSAs) were determined by integration of the 


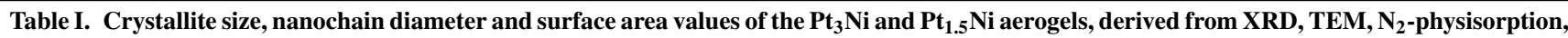
$\mathrm{H}_{\mathrm{upd}}$ and CO stripping analysis.

\begin{tabular}{|c|c|c|c|c|c|c|c|}
\hline \multirow[b]{2}{*}{ Catalyst } & \multicolumn{2}{|c|}{ Size $[\mathrm{nm}]$} & \multicolumn{5}{|c|}{ Surface area $\left[\mathrm{m}^{2} / \mathrm{g}_{\mathrm{Pt}}\right]$} \\
\hline & XRD & TEM & $\mathrm{XRD}_{\text {calc }}{ }^{1}$ & $\mathrm{TEM}_{\mathrm{calc}}{ }^{1}$ & $\mathrm{H}_{\text {upd }}{ }^{2}$ & CO strip..$^{3}$ & $\mathrm{~N}_{2}$-physis. \\
\hline $\mathrm{Pt}_{3} \mathrm{Ni}$ & $6.7 \pm 1.3$ & $5.6 \pm 1.2$ & $35 \pm 7$ & $41 \pm 9$ & $32 \pm 2$ & $30 \pm 2$ & 55 \\
\hline $\mathrm{Pt}_{1.5} \mathrm{Ni}$ & $6.0 \pm 1.0$ & $5.5 \pm 1.1$ & $46 \pm 8$ & $51 \pm 10$ & $30 \pm 1$ & $28 \pm 1$ & 58 \\
\hline
\end{tabular}

\footnotetext{
${ }^{1}$ Surface area values based on the assumption of nanowires with a cylindrical geometry of diameter equal to the one averaged from XRD or TEM measurements, along with alloy density values of $19.0\left(\mathrm{Pt}_{3} \mathrm{Ni}\right)$ and $17.3 \mathrm{~g} / \mathrm{cm}^{3}\left(\mathrm{Pt}_{1.5} \mathrm{Ni}\right)$.

${ }^{2}$ Extracted from the integration of $\mathrm{H}_{\text {upd }}$ desorption peaks (cf. Fig. SI-5) using the double layer current as an extended baseline and averaged on the basis of 3 independent measurements.

${ }^{3}$ Based on the integration of the charges for the CO oxidation peak using the subsequent CV as a baseline (cf. Fig. SI-5) and averaged on the basis of 3 independent measurements.
}

charges corresponding to the underpotential deposition of hydrogen $\left(\mathrm{H}_{\text {upd }}\right)$ on $\mathrm{Pt}^{27}$ and the oxidation of a monolayer of carbon monoxide potentiostatically adsorbed on the Pt-surface (CO stripping) ) $^{28,29}$ (see Fig. SI-5). As summarized in Table I, the ECSAs of both aerogels are similar $\left(\approx 30 \mathrm{~m}^{2} / \mathrm{g}_{\mathrm{Pt}}\right)$ and $\approx 20-40 \%$ lower than the surface areas obtained from BET plots or estimated from the XRD- or TEM-derived diameters on the basis of a cylindrical geometry approximation. This difference most likely results from the interconnectivity between the nanowires that form the tridimensional network and from the lack of wettability of micropores in the nanostructures, which are accessible to the $\mathrm{N}_{2}$-adsorbate used in the physisorption measurements.

To elucidate the aerogels' electronic and local structure, X-ray absorption spectroscopy (XAS) at the $\mathrm{Ni} \mathrm{K}$ edge $(8333 \mathrm{eV})$ was used to characterize the $\mathrm{Pt}_{3} \mathrm{Ni}$ and $\mathrm{Pt}_{1.5} \mathrm{Ni}$ aerogels, as well as a $\mathrm{Ni}(\mathrm{OH})_{2}$ ( $\beta$-phase) reference sample. ${ }^{30}$ The $\mathrm{X}$-ray absorption near edge structure (XANES) region within $\pm 30 \mathrm{eV}$ of the absorption edge reveals significant differences among the Pt-Ni aerogels (see Fig. 2A). The position of the absorption edge of the $\mathrm{Pt}_{1.5} \mathrm{Ni}$ aerogel is shifted to higher energy and the white line intensity is increased compared to that of the $\mathrm{Pt}_{3} \mathrm{Ni}$ aerogel, suggesting a partial oxidation of $\mathrm{Ni}$ in the $\mathrm{Pt}_{1.5} \mathrm{Ni}$ aerogel. ${ }^{31}$

Considering the resembling nanochain diameters of both materials and the 2-fold larger $\mathrm{Ni}$-concentration of the $\mathrm{Pt}_{1.5} \mathrm{Ni}$ sample, this difference in the Ni-oxidation states cannot be exclusively assigned to the Ni on the aerogels' surfaces (which would get oxidized upon contact with air). Alternatively, this discrepancy could be additionally related to the formation of $\mathrm{Ni}$-(hydr)oxide sidephase(s) in the $\mathrm{Pt}_{1.5} \mathrm{Ni}$ aerogel, implying that only a fraction of the $\mathrm{Ni}$ is involved in the alloying with Pt. This hypothesis is further supported by the good agreement between the XANES recorded for the $\mathrm{Pt}_{1.5} \mathrm{Ni}$ aerogel and the corresponding fit as a linear combination of the $\mathrm{Pt}_{3} \mathrm{Ni}$ aerogel and $\mathrm{Ni}(\mathrm{OH})_{2}$ spectra, displayed in Figure 2B. The best fit was obtained for relative weights of $75 \%$ and $25 \%$ for $\mathrm{Pt}_{3} \mathrm{Ni}$ and $\mathrm{Ni}(\mathrm{OH})_{2}$ respectively, confirming that a significant amount of the $\mathrm{Ni}$ in the $\mathrm{Pt}_{1.5} \mathrm{Ni}$ aerogel is present in the form of a Ni-(hydr)oxide phase. Surface-sensitive X-ray photoelectron spectroscopy (XPS) in the $\mathrm{Ni} 2 \mathrm{p}_{3 / 2}$ region (cf. Fig. SI-6) also corroborates this observation. The sharp peak at $\approx 852.6 \mathrm{eV}$ in the spectrum of $\mathrm{Pt}_{3} \mathrm{Ni}$ is associated with $\mathrm{Ni}^{0},{ }^{32-34}$ whereas the $\mathrm{Pt}_{1.5} \mathrm{Ni}$ spectrum only contains a minor shoulder at the same energy, pointing at a larger content of $\mathrm{Ni}^{0}$ in $\mathrm{Pt}_{3} \mathrm{Ni}$ when compared to $\mathrm{Pt}_{1.5} \mathrm{Ni}$. Moreover, this finding is in qualitative agreement with previous work by Park et al. ${ }^{26}$ who investigated carbon-supported $\mathrm{Pt}_{3} \mathrm{Ni}$ and $\mathrm{PtNi}$ nanoparticles of 3-4 nm diameter prepared by an aqueous-based approach similar to the one used here.

Next, the local structure of both Pt-Ni aerogels was studied by additionally analyzing the extended X-ray absorption fine structure (EXAFS) spectra collected at both the $\mathrm{Pt}_{3}(11564 \mathrm{eV})$ and the $\mathrm{Ni} \mathrm{K}$ $(8333 \mathrm{eV})$ edge. The outcome of the simultaneous first shell fit of the Pt $\mathrm{L}_{3}$ and $\mathrm{Ni} \mathrm{K}$ EXAFS spectra of $\mathrm{Pt}_{3} \mathrm{Ni}$ is summarized in Table II, and the Fourier transformed (FT) EXAFS spectra and corresponding fits are shown in Figure 3. The close agreement between the experimental data and the corresponding fits at the $\mathrm{Pt}_{3}$ and Ni $\mathrm{K}$ edge is discernable from Fig. 3 and confirmed by the low R-factor value. ${ }^{35}$ Additionally, the properties of our $\mathrm{Pt}_{3} \mathrm{Ni}$ aerogel and those reported
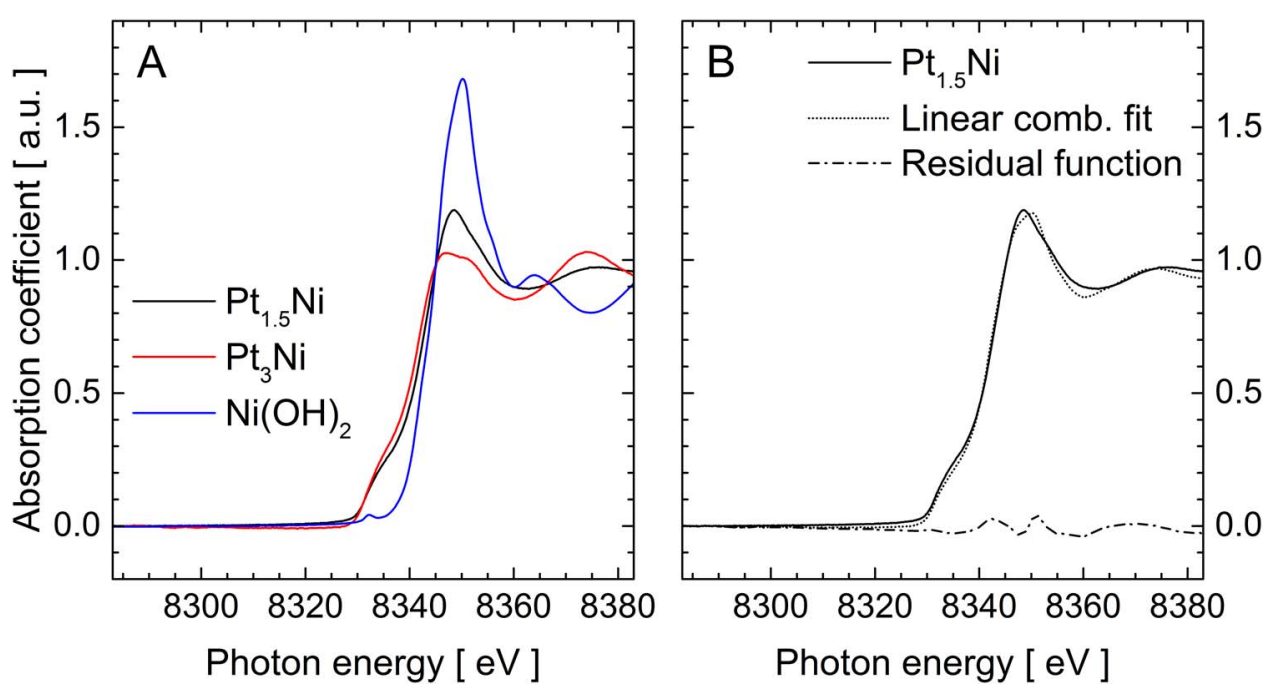

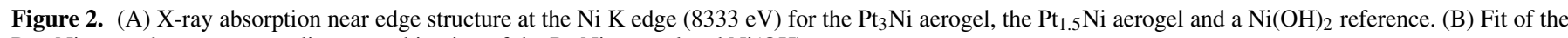
$\mathrm{Pt}_{1.5} \mathrm{Ni}$ aerogel spectrum as a linear combination of the $\mathrm{Pt}_{3} \mathrm{Ni}$ aerogel and $\mathrm{Ni}(\mathrm{OH})_{2}$ spectra. 
Table II. Structural parameters derived from the fitting of the EXAFS ( $\mathrm{Pt}_{3}$ and $\mathrm{Ni} \mathrm{K}$ edges) of the $\mathrm{Pt}_{3} \mathrm{Ni}$ aerogel. Values in brackets are extracted from Ref. 36 and were determined for a $\mathrm{Pt}_{3} \mathrm{Ni} / \mathrm{C}$ catalyst of similar particle size. Note that $\mathrm{R}$-factor values below 0.02 are regarded as indicative of a good quality EXAFS fit. $^{35}$

\begin{tabular}{ccccc} 
Coord. shell & Coord. number & Bond length $[\AA]$ & $\sigma^{2}\left[10^{-3} \AA^{2}\right]$ & R-factor \\
\hline Pt-Pt & $7.5 \pm 1.0(8.0)$ & $2.71 \pm 0.01(2.71)$ & $7 \pm 1$ & 0.01 \\
Pt-Ni & $2.5 \pm 0.7(2.0)$ & $2.66 \pm 0.03(2.65)$ & $13 \pm 1$ & 0.01 \\
Ni-Pt & $5.0 \pm 1.2$ & $2.66 \pm 0.03$ & $13 \pm 1$ & 0.01 \\
Ni-Ni & $2.8 \pm 1.1$ & $2.58 \pm 0.03$ & $12 \pm 4$ & 0.01
\end{tabular}

for a $\mathrm{Pt}_{3} \mathrm{Ni} / \mathrm{C}$ catalyst with a similar particle size in Ref. 36 are very comparable (cf. Table II), as one would expect from the similarities between the individual building blocks of both materials, i.e. $\mathrm{Pt}_{3} \mathrm{Ni}$ nanoparticles.

Moreover, the Cowley's short range order parameter $(\alpha)$ which quantifies the homogeneity of bimetallic nanoparticles can be derived from the EXAFS analysis as follow, ${ }^{37,38}$

$$
\alpha=1-\frac{C N_{P t-N i} /\left(C N_{P t-P t}+C N_{P t-N i}\right)}{x_{N i}}
$$

whereby $C N_{P t-N i}$ and $C N_{P t-P t}$ refer to the Pt-to-Ni and Pt-to-Pt coordination numbers, respectively, and $\mathrm{x}_{\mathrm{Ni}}$ stands for the molar concentration of $\mathrm{Ni}$ in the alloy (i.e. 0.25). This calculation yields a value of $0.0 \pm 0.3$ that is indicative of a homogeneously random alloy. ${ }^{37}$ Our attempt at fitting the first shell EXAFS of $\mathrm{Pt}_{1.5} \mathrm{Ni}$ considering Pt$\mathrm{Pt}, \mathrm{Pt}-\mathrm{Ni}$, Ni-Pt and Ni-Ni scattering contributions was unsuccessful (not shown here), possibly due to the sample inhomogeneity caused

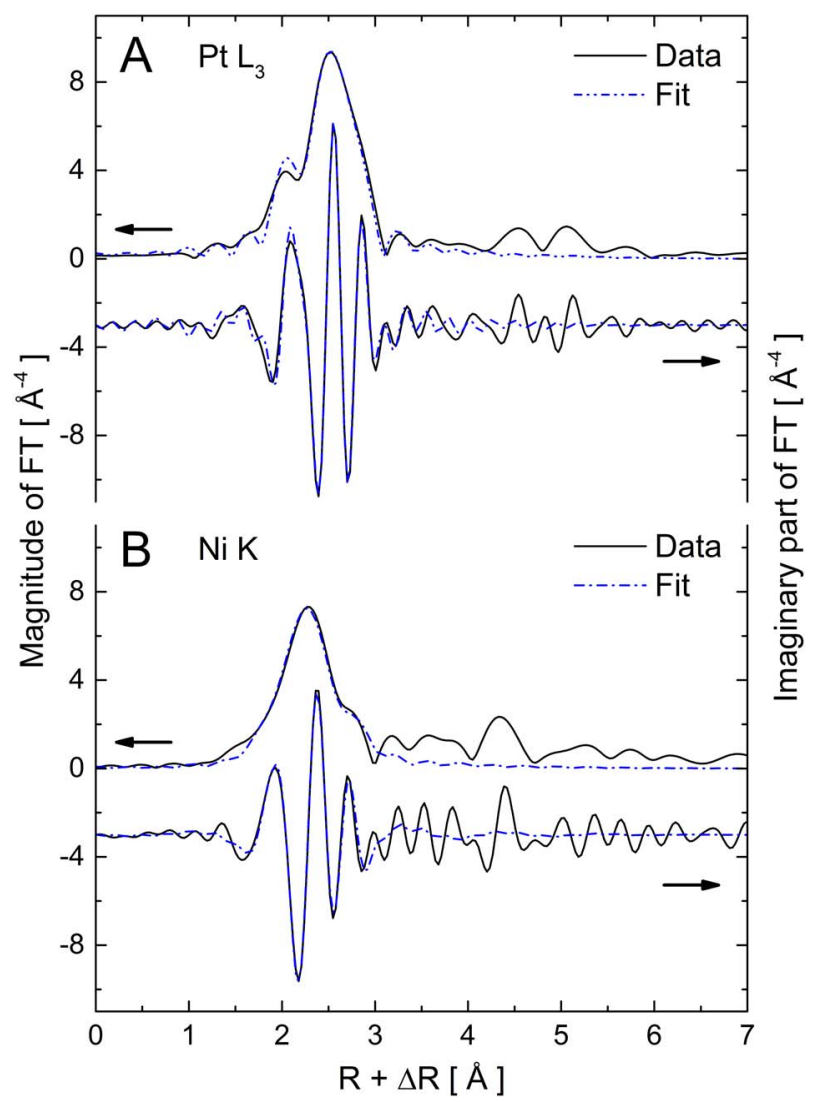

Figure 3. EXAFS fit and experimental data $\left(\mathrm{k}^{3}\right.$-weighted) in R-space (uncorrected for phase shifts) for $\mathrm{Pt}_{3} \mathrm{Ni}$ aerogel at the $\mathrm{Pt}_{3}$ (A) and $\mathrm{Ni} \mathrm{K}$ edge (B).

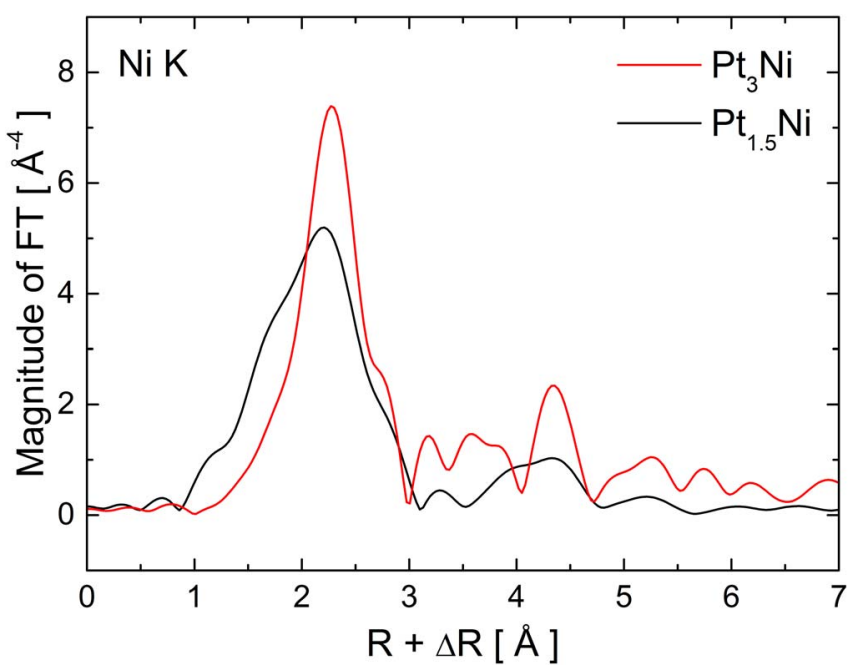

Figure 4. Ni K edge EXAFS Fourier transformation $\left(\mathrm{k}^{3}\right.$-weighted) in R-space (uncorrected for phase shifts) for $\mathrm{Pt}_{3} \mathrm{Ni}$ and $\mathrm{Pt}_{1.5} \mathrm{Ni}$ aerogel.

by the presence of a Ni-(hydr)oxide sidephase inferred above. Again, this finding is endorsed upon comparison of the Ni K edge Fourier transformed EXAFS for both aerogels (see Fig. 4), in which $\mathrm{Pt}_{1.5} \mathrm{Ni}$ displays a first coordination shell between 1.5-1.8 $\AA$ indicative of $\mathrm{Ni}-\mathrm{O}$ scattering ${ }^{31}$ that is only minor for the $\mathrm{Pt}_{3} \mathrm{Ni}$ aerogel.

In a final effort to verify the hypothesized presence of two separate phases in the $\mathrm{Pt}_{1.5} \mathrm{Ni}$ aerogel, the surface compositions of the as prepared $\mathrm{Pt}_{3} \mathrm{Ni}$ and $\mathrm{Pt}_{1.5} \mathrm{Ni}$ aerogels were investigated electrochemically by cyclic voltammetry $(\mathrm{CV})$. Since $\mathrm{Ni}$ is thermodynamically prone to dissolution in acid electrolyte, ${ }^{39}$ the measurements were initially carried out in alkaline medium $(0.1 \mathrm{M} \mathrm{NaOH})$ to prevent its leaching from the alloy surface. ${ }^{27}$ The presence of Pt and Ni on the catalyst surface is indicated by element specific features in the CVs, whereby the peaks between $\approx 0.05-0.4 \mathrm{~V}$ vs. reversible hydrogen electrode $\left(\mathrm{V}_{\mathrm{RHE}}\right)$ are associated to $\mathrm{H}_{\text {upd }}$ on polycrystalline $\mathrm{Pt}^{40}$ For Ni, the oxidation of $\mathrm{Ni}(\mathrm{OH})_{2}$ to $\mathrm{NiOOH}$ at $\approx 1.4 \mathrm{~V}_{\mathrm{RHE}}$ and its quasi-reversible, subsequent reduction in the negative going scan provides such a characteristic feature. $^{41}$

According to the solid curves in Fig. 5 (CVs in alkaline electrolyte between 0.05 and $1.6 \mathrm{~V}_{\mathrm{RHE}}$ ), both aerogels exhibit Pt-related $\mathrm{H}_{\text {upd }}$ features, but only $\mathrm{Pt}_{1.5} \mathrm{Ni}$ displays pronounced $\mathrm{Ni}(\mathrm{OH})_{2}$ oxidation/ $\mathrm{NiOOH}$ reduction peaks as well. Consequently, the $\mathrm{Pt}_{3} \mathrm{Ni}$ surface contains but traces of $\mathrm{Ni}$, as one would expect from the nominal composition $(\mathrm{Pt}: \mathrm{Ni}=3: 1)$ and alloy homogeneity derived from the XAS-analysis, whereas $\mathrm{Pt}_{1.5} \mathrm{Ni}$ contains a significant amount of surface $\mathrm{Ni}$ possibly in the form of a (hydr)oxide phase, further supporting the hypothesis that not all $\mathrm{Ni}$ is present as a Pt-Ni alloy phase.

To probe the stability of this surface Ni species in acid, the experiment was continued by immersing each electrode in a separated electrochemical cell filled with $0.1 \mathrm{M} \mathrm{HClO}_{4}$ electrolyte, followed by the recording of 25 potential cycles between 0.05 and $1.0 \mathrm{~V}_{\mathrm{RHE}}$. Subsequently, CVs were again recorded in $0.1 \mathrm{M} \mathrm{NaOH}$ to identify possible changes in the surface. Interestingly, at this point both materials display very similar voltammetric profiles, with a complete absence of redox transitions at $\approx 1.4 \mathrm{~V}_{\mathrm{RHE}}$ that indicates the complete dissolution of the $\mathrm{Ni}$-(hydr)oxide sidephase upon conditioning in acid medium.

After this structural characterization, the ORR activity of both Pt-Ni aerogels in acid medium $\left(0.1 \mathrm{M} \mathrm{HClO}_{4}\right)$ was determined using rotating disk electrode (RDE) voltammetry, whereby a commercial $\mathrm{Pt} / \mathrm{C}$ catalyst (30\% Pt/Vulcan XC-72) served as benchmark. The ECSA- and mass-specific ORR activities at $0.95 \mathrm{~V}_{\mathrm{RHE}}$ are shown in Fig. 6. The average ECSA values from $\mathrm{H}_{\text {upd }}$ and $\mathrm{CO}$ stripping analysis summarized in Table I were used for normalization. The potential 
of $0.95 \mathrm{~V}_{\mathrm{RHE}}$ was chosen instead of $0.9 \mathrm{~V}_{\mathrm{RHE}}$ because the latter was too close to the diffusion-limited regime to allow for accurate correction of mass transport losses (cf. polarization curves in Figure SI-7). ${ }^{42}$ Moreover, mitigating such high currents by reducing the catalyst loading on the electrode was not possible, since minimal loadings of $30 \mu \mathrm{g}_{\mathrm{Pt}} / \mathrm{cm}^{2}$ electrode were required for both aerogels to fully cover the glassy carbon disk.

As displayed in Fig. 6A, both aerogels show a $\approx 3$-fold increase of the ECSA-specific activity vs. Pt/C that can be partially assigned to their larger particle size (cf. average aerogel diameters of $5.5 \mathrm{~nm}$ listed in Table I, vs. the $3.4 \mathrm{~nm}$ of the $30 \% \mathrm{Pt} / \mathrm{C}$ benchmark estimated in Ref. 43). However, the limited sensitivity of the ORR-kinetics to the $\mathrm{Pt}$ particle size within the corresponding range of ECSA-values $(\approx 50$ $\mathrm{m}^{2} / \mathrm{g}_{\mathrm{Pt}}$ for Pt/C vs. $\approx 30 \mathrm{~m}^{2} / \mathrm{g}_{\mathrm{Pt}}$ for the PtNi-aerogels, see Fig. 6A) implies that the aerogels' larger size can only account for an activity increase of $\approx 20 \% ., 27$ Thus, the great majority of the observed $\approx 3$ fold activity enhancement can be explained by a down shift of the d-band center through alloying with $\mathrm{Ni}^{44}$ According to literature, this shift decreases the fractional coverage of spectator species at a given potential and increases the number of free sites for $\mathrm{O}_{2}$ adsorption and subsequent ORR activity. ${ }^{45}$

Upon conversion of these figures into mass-specific ORR activities (Fig. 6B), $\mathrm{Pt}_{3} \mathrm{Ni}$ and $\mathrm{Pt}_{1.5} \mathrm{Ni}$ reach the DOE ORR activity target at $0.95 \mathrm{~V}_{\mathrm{RHE}}$ that was extrapolated from the reported value ${ }^{21}$ of $440 \mathrm{~A} / \mathrm{g}_{\mathrm{Pt}}$ at $0.9 \mathrm{~V}_{\mathrm{RHE}}$ assuming a Tafel slope of $60 \mathrm{mV} \mathrm{dec}{ }^{-1}$ consistent with our measurements (cf. Fig. SI-7) ${ }^{46}$ Following the same approach, the ORR activity values at $0.95 \mathrm{~V}_{\mathrm{RHE}}$ for both $\mathrm{Pt}-\mathrm{Ni}$ aerogels $\left(\approx 62 \pm 5 \mathrm{~A} / \mathrm{g}_{\mathrm{Pt}}\right)$ can be extrapolated to $\approx 422 \pm 34 \mathrm{~A} / \mathrm{g}_{\mathrm{Pt}}$ at $0.9 \mathrm{~V}_{\mathrm{RHE}}$, in good agreement with recent reports on de-alloyed $\mathrm{Pt}$ $\mathrm{Ni} / \mathrm{C}$ catalysts based on $\mathrm{RDE}^{47}$ and fuel cell ${ }^{48}$ tests. The almost identical ECSA and ORR activity values for the two aerogels agree with the above conclusion that their surface compositions become much alike after a few conditioning cycles in $0.1 \mathrm{M} \mathrm{HClO}_{4}$ (see Fig. 5), in which surface- $\mathrm{Ni}$ and $\mathrm{Ni}(\mathrm{OH})_{2}$ sidephases dissolve into the acid electrolyte.

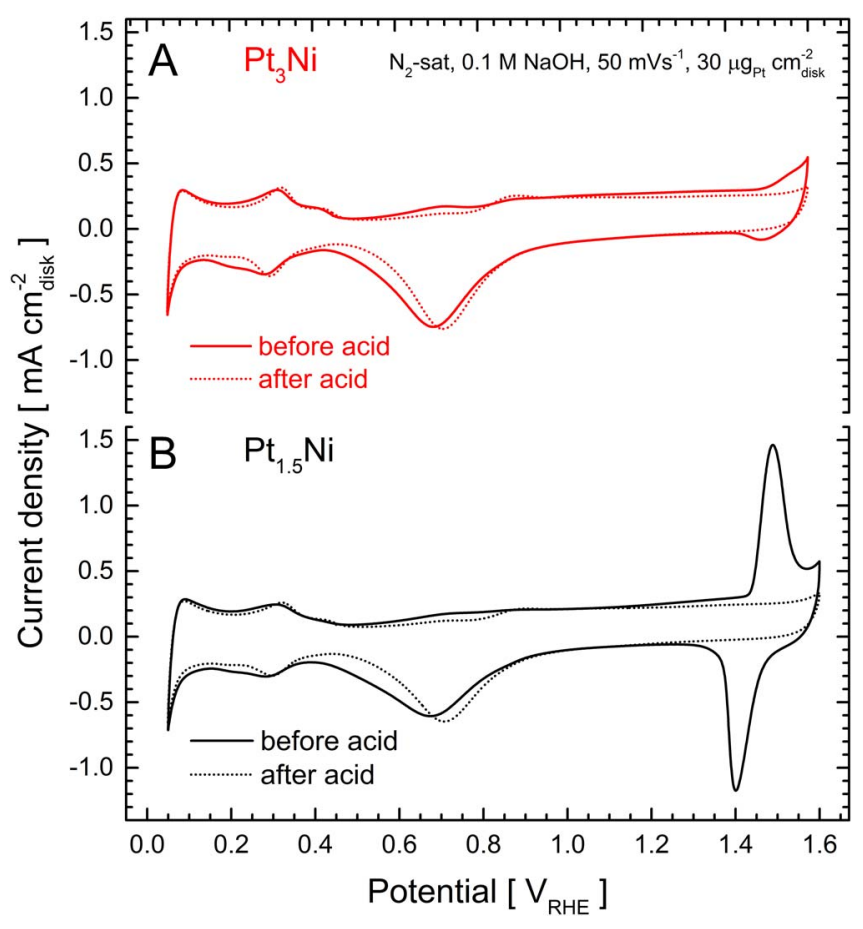

Figure 5. Cyclic voltammograms (CVs) in $\mathrm{N}_{2}$-saturated $0.1 \mathrm{M} \mathrm{NaOH}$ electrolyte at $50 \mathrm{mV} \mathrm{s}^{-1}$ of $\mathrm{Pt}_{3} \mathrm{Ni}(\mathrm{A})$ and $\mathrm{Pt}_{1.5} \mathrm{Ni}(\mathrm{B})$ aerogel. CVs before (solid) and after (dotted) 25 conditioning cycles in $0.1 \mathrm{M} \mathrm{HClO}_{4}$ electrolyte between 0.05 and $1.0 \mathrm{~V}_{\mathrm{RHE}}$ are shown.
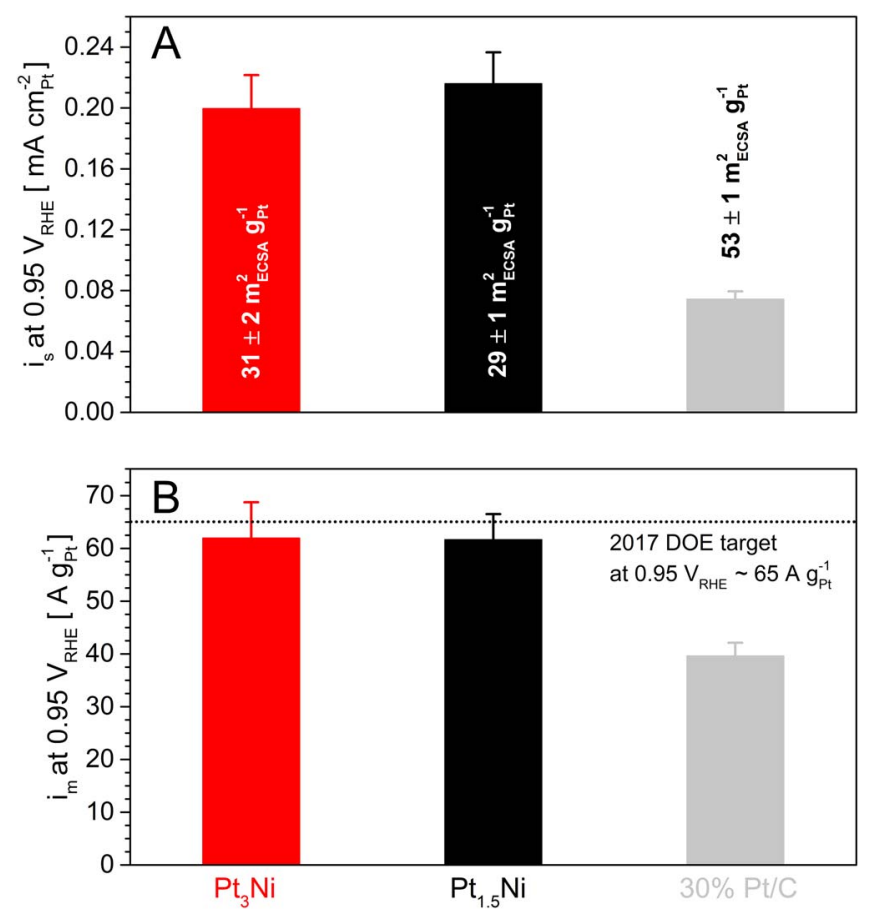

Figure 6. Pt-ECSA (A) and mass-specific (B) ORR activity values at 0.95 $\mathrm{V}_{\mathrm{RHE}}$ for Pt-Ni aerogels and Pt/C (averaged from 3 independent measurements). The dotted line represents the DOE ORR activity target at $0.95 \mathrm{~V}_{\mathrm{RHE}}$, extrapolated from the benchmark value of $440 \mathrm{~A} / \mathrm{g}_{\mathrm{Pt}}$ at $0.9 \mathrm{~V}_{\mathrm{RHE}}{ }^{21}$ assuming a Tafel slope of $60 \mathrm{mV} \mathrm{dec}{ }^{-1} .{ }^{46}$ Activity values were extracted from anodic polarization curves in $\mathrm{O}_{2}$-saturated $0.1 \mathrm{M} \mathrm{HClO}_{4}$ electrolyte $\left(5 \mathrm{mV} \mathrm{s}^{-1}\right)$, corrected for IR-drop and mass transport losses (Koutecky-Levich equation). Reported ECSA values are averaged from results for $\mathrm{H}_{\text {upd }}$ and $\mathrm{CO}$ stripping analysis (cf. Table I).

\section{Conclusions}

In summary, we have presented a new facile synthesis for the preparation of Pt-Ni bimetallic aerogels. Extensive sample characterization suggested complete alloy formation in the case of $\mathrm{Pt}_{3} \mathrm{Ni}$, along with limited alloying upon targeting larger $\mathrm{Ni}$-contents using this synthetic approach. Electrochemical measurements of the aerogels' catalytic activity toward oxygen reduction revealed a 3-fold ECSA-specific activity increase when compared to commercial $\mathrm{Pt} / \mathrm{C}$ catalysts that is in agreement with reports in the literature. Additionally, the massspecific ORR activity of the Pt-Ni aerogels is comparable to that of state-of-the-art, de-alloyed $\mathrm{Pt}-\mathrm{Ni} / \mathrm{C}$ materials, and meets the DOEtarget value for automotive FC application. Future work will therefore focus on investigating the stability of these Pt-Ni aerogels under PEFC-relevant working conditions and comparing their behavior to that of commercial Pt/C catalysts, as to verify the stability enhancement expected from the absence of a carbon support in these novel materials. $^{49}$

\section{Acknowledgment}

The authors thank the Swiss Light Source for providing beamtime at the SuperXAS beamline. The support of Dr. Xi Cheng, Dr. Emiliana Fabbri and Dr. Annett Rabis for XRD and XPS measurements is also greatly acknowledged. We are grateful to Dr. Mario El Kazzi for helpful discussions regarding the interpretation of the Ni 2p XPS spectra and thank Dr. David McNear for the provision of the $\mathrm{Ni}(\mathrm{OH})_{2}$ XAS spectrum. This work was funded by the Swiss National Science Foundation (20001E_151122/1), the German Research Foundation (EY 16/18-1) and the European Research Council (ERC AdG 2013 AEROCAT). 


\section{References}

1. F. T. Wagner, B. Lakshmanan, and M. F. Mathias, J. Phys. Chem. Lett., 1, 2204 (2010).

2. D. Papageorgopoulos, http://www.hydrogen.energy.gov/pdfs/review15/fc000_ papageorgopoulos_2015_o.pdf (accessed 09.03.2016).

3. C. Wang, M. Chi, D. Li, D. Strmcnik, D. van der Vliet, G. Wang, V. Komanicky, K. C. Chang, A. P. Paulikas, D. Tripkovic, J. Pearson, K. L. More, N. M. Markovic, and V. R. Stamenkovic, J. Am. Chem. Soc., 133, 14396 (2011).

4. A. Rabis, P. Rodriguez, and T. J. Schmidt, ACS Catal., 2, 864 (2012).

5. S. M. Alia, B. A. Larsen, S. Pylypenko, D. A. Cullen, D. R. Diercks, K. C. Neyerlin, S. S. Kocha, and B. S. Pivovar, ACS Catal., 4, 1114 (2014).

6. S. M. Alia, S. Pylypenko, K. C. Neyerlin, D. A. Cullen, S. S. Kocha, and B. S. Pivovar, ACS Catal., 4, 2680 (2014).

7. S. M. Alia, K. Jensen, C. Contreras, F. Garzon, B. Pivovar, and Y. S. Yan, ACS Catal., 3, 358 (2013).

8. M. K. Debe, ECS Trans., 45, 47 (2012).

9. G. Ozouf, G. Cognard, F. Maillard, L. Guetaz, M. Heitzmann, and C. Beauger, ECS Trans., 69, 1207 (2015).

10. A. Patru, A. Rabis, S. E. Temmel, R. Kotz, and T. J. Schmidt, Catal. Today, 262, 161 (2016).

11. E. Fabbri, A. Rabis, R. Kotz, and T. J. Schmidt, Phys. Chem. Chem. Phys, 16, 13672 (2014).

12. E. Fabbri, A. Patru, A. Rabis, R. Kötz, and T. J. Schmidt, CHIMIA, 68, 217 (2014).

13. A. Bonnefont, P. Ruvinskiy, M. Rouhet, A. Orfanidi, S. Neophytides, and E. Savinova, WIREs Energy Environ., 3, 505 (2014).

14. A. K. Herrmann, P. Formanek, L. Borchardt, M. Klose, L. Giebeler, J. Eckert, S. Kaskel, N. Gaponik, and A. Eychmuller, Chem. Mater, 26, 1074 (2014).

15. W. Liu, A.-K. Herrmann, N. C. Bigall, P. Rodriguez, D. Wen, M. Oezaslan, T. J. Schmidt, N. Gaponik, and A. Eychmüller, Acc. Chem. Res., 48, 154 (2015).

16. C. Zhu, D. Du, A. Eychmuller, and Y. Lin, Chem. Rev., 115, 8896 (2015).

17. X. Yu, D. Wang, Q. Peng, and Y. Li, Chem. Eur. J., 19, 233 (2013).

18. J. Lai, L. Zhang, W. Qi, J. Zhao, M. Xu, W. Gao, and G. Xu, ChemCatChem, 6, 2253 (2014).

19. M. Xiao, S. Li, X. Zhao, J. Zhu, M. Yin, C. Liu, and W. Xing, ChemCatChem, 6, 2825 (2014).

20. W. Liu, P. Rodriguez, L. Borchardt, A. Foelske, J. Yuan, A. K. Herrmann, D. Geiger, Z. Zheng, S. Kaskel, N. Gaponik, R. Kotz, T. J. Schmidt, and A. Eychmuller, Angew. Chem. Int. Ed., 52, 9849 (2013).

21. O. Gröger, H. A. Gasteiger, and J. P. Suchsland, J. Electrochem. Soc., 162, A2605 (2015).

22. O. Müller, M. Nachtegaal, J. Just, D. Lützenkirchen-Hecht, and R. Frahm, J. Synchrotron Rad., 23, 260 (2016).

23. B. Ravel and M. Newville, J. Synchrotron Rad., 12, 537 (2005).

24. S. Henning, J. Herranz, and H. A. Gasteiger, J. Electrochem. Soc., 162, F178 (2015)

25. K. S. W. Sing, D. H. Everett, R. A. W. Haul, L. Moscou, R. A. Pierotti, J. Rouquerol, and T. Siemieniewska, Pure Appl. Chem., 57, 603 (1985).
26. K.-W. Park, J.-H. Choi, B.-K. Kwon, S.-A. Lee, Y.-E. Sung, H.-Y. Ha, S.-A. Hong, H. Kim, and A. Wieckowski, J. Phys. Chem. B, 106, 1869 (2002).

27. H. A. Gasteiger, S. S. Kocha, B. Sompalli, and F. T. Wagner, Appl. Catal. B: Environ., 56, 9 (2005).

28. K. J. J. Mayrhofer, D. Strmcnik, B. B. Blizanac, V. Stamenkovic, M. Arenz, and N. M. Markovic, Electrochim. Acta, 53, 3181 (2008).

29. F. Maillard, M. Eikerling, O. V. Cherstiouk, S. Schreier, E. Savinova, and U. Stimming, Faraday Discuss., 125, 357 (2004).

30. D. H. McNear Jr, R. L. Chaney, and D. L. Sparks, Geochim. et Cosmochim. Acta, 71, 2190 (2007).

31. N. Becknell, Y. Kang, C. Chen, J. Resasco, N. Kornienko, J. Guo, N. M. Markovic, G. A. Somorjai, V. R. Stamenkovic, and P. Yang, J. Am. Chem. Soc., 137, 15817 (2015).

32. M. C. Biesinger, B. P. Payne, L. W. M. Lau, A. Gerson, and R. S. C. Smart, Surf Interface Anal., 41, 324 (2009).

33. A. P. Grosvenor, M. C. Biesinger, R. S. Smart, and N. S. McIntyre, Surf. Sci., 600 , 1771 (2006).

34. C. Chen, Y. Kang, Z. Huo, Z. Zhu, W. Huang, H. L. Xin, J. D. Snyder, D. Li, J. A. Herron, M. Mavrikakis, M. Chi, K. L. More, Y. Li, N. M. Markovic, G. A. Somorjai, P. Yang, and V. R. Stamenkovic, Science, 343, 1339 (2014).

35. bruceravel.github.io/demeter/artug/fit/happiness.html (accessed 09.03.2016).

36. F. H. B. Lima, J. R. C. Salgado, E. R. Gonzalez, and E. A. Ticianelli, J. Electrochem. Soc., 154, A369 (2007).

37. A. I. Frenkel, Q. Wang, S. I. Sanchez, M. W. Small, and R. G. Nuzzo, J. Chem. Phys., 138, 064202 (2013).

38. A. I. Frenkel, A. Yevick, C. Cooper, and R. Vasic, Annu. Rev. Anal. Chem., 4, 23 (2011).

39. M. Pourbaix, Atlas of electrochemical equilibria in aqueous solutions, Pergamon Press, Oxford (1966).

40. P. J. Rheinländer, J. Herranz, J. Durst, and H. A. Gasteiger, J. Electrochem. Soc., 161, F1448 (2014).

41. D. S. Hall, C. Bock, and B. R. MacDougall, J. Electrochem. Soc., 161, H787 (2014).

42. W. Sheng, H. A. Gasteiger, and Y. Shao-Horn, J. Electrochem. Soc., 157, B1529 (2010).

43. F. Maillard, M. Martin, F. Gloaguen, and J. M. Léger, Electrochim. Acta, 47, 3431 (2002).

44. V. R. Stamenkovic, B. Fowler, B. S. Mun, G. Wang, P. N. Ross, C. A. Lucas, and N. M. Markovic, Science, 315, 493 (2007)

45. V. R. Stamenkovic, B. S. Mun, M. Arenz, K. J. Mayrhofer, C. A. Lucas, G. Wang, P. N. Ross, and N. M. Markovic, Nat. Mater., 6, 241 (2007)

46. U. A. Paulus, T. J. Schmidt, H. A. Gasteiger, and R. J. Behm, J. Electroanal. Chem., 495, 134 (2001).

47. L. Gan, M. Heggen, S. Rudi, and P. Strasser, Nano Lett., 12, 5423 (2012).

48. B. H. Han, C. E. Carlton, A. Kongkanand, R. S. Kukreja, B. R. Theobald, L. Gan, R. O'Malley, P. Strasser, F. T. Wagner, and Y. Shao-Horn, Energ. Environ. Sci., 8, 258 (2015).

49. T. Tamaki, H. Kuroki, S. Ogura, T. Fuchigami, Y. Kitamoto, and T. Yamaguchi, Energy Environ. Sci., 8, 3545 (2015). 